\title{
LA JURISPRUDENCIA DEL TRIBUNAL SUPREMO SOBRE LA POSIBILIDAD DE EXIGIR LA APLICACIÓN DEL CONVENIO COLECTIVO DEL LUGAR DE EJECUCIÓN EN LA CONTRATACIÓN PÚBLICA*
}

\author{
Jurisprudence of the Supreme Court on the Possibility \\ of Demanding Compliance with the Collective Agreement \\ of the Place of Execution in the Public Procurement
}

\author{
Eider Larrazabal Astigarraga \\ Profesora Adjunta de Derecho del Trabajo y de la Seguridad Social \\ Universidad del País Vasco / Euskal Herriko Unibertsitatea
}

\section{ABSTRACT}

Se analiza la jurisprudencia del Tribunal Supremo sobre la posibilidad de exigir el cumplimiento del convenio colectivo del lugar de ejecución en el marco de la contratación pública. A tal fin, se analizarán las cuatro sentencias recaidas al respecto, destacando las dos principales claves del asunto a tratar: por un lado, la necesidad de ostentar la competencia normativa para imponer una cláusula social de tales caracteristicas y, por otro lado, su compatibilidad con la actual normativa vigente en

\footnotetext{
* Trabajo realizado en el marco del Grupo de investigación GIU 2015/04 (UPV/EHU), cuya Investigadora Principal es Olga Fotinopoulou Basurko.
} 
materia de convenios colectivos, en especial, la relativa a la ultraactividad y la prioridad aplicativa del convenio de empresa.

Palabras clave: Tribunal Supremo, contratación pública, convenio colectivo del lugar de ejecución, competencia normativa, ultraactividad.

We analyze the jurisprudence of the Supreme Court on the possibility of demanding compliance with the collective agreement of the place of execution in the context of public procurement. To this end, the four judgments relayed in this respect will be analyzed, highlighting the two main clues of the subject: on the one hand, the need to have the normative competence to impose a social clause of such characteristics and, on the other hand, their compatibility with the current legislation on collective agreements, in particular, the one relating to ultraactivity and the application priority of the business agreement.

Keywords: Supreme Court, public procurement, collective agreement of the place of execution, normative competence, ultraactivity.

Kontratazio publikoaren esparruan kontratua burutzen den lekuko hitzarmen kolektiboa betetzeko aukeraren inguruko Auzitegi Gorenaren jurisprudentzia aztertzen da. Helburu horrekin, gaiaren inguruan ebatzi dituen lau epaiak jorratuko dira, gaiaren bi gako nagusienak azpimarratuz: alde batetik, mota horretako klausula soziala ezartzeko arau-eskuduntza izateko beharra eta, beste alde batetik, bere bateragarritasuna indarrean dagoen hitzarmen kolektiboen araudiarekin, bereziki, ultraaktibitateraekin eta enpresako hitzarmenaren lehentasun printzipioarekin.

Hitz gakoak: Auzitegi Gorena, kontratazio publikoa, lekuko hitzarmen kolektiboa, arau-eskuduntza, ultraaktibitatea. 


\section{SUMARIO}

Sumario. 1. Introducción. 2. La importancia de aplicar el convenio colectivo del lugar de ejecución en los contratos públicos. 3. Análisis de la jurisprudencia del Tribunal Supremo. 4. Conclusiones. 5. Bibliografía.

\section{Introducción}

En este trabajo se analiza la jurisprudencia del Tribunal Supremo sobre la posibilidad de exigir la aplicación del convenio colectivo del lugar de ejecución en la contratación pública. Como tendremos la oportunidad de analizar, dicha jurisprudencia resulta conflictiva y, en muchos casos, confusa. Es por ello que merece la pena su estudio, ya que la cuestión carece hoy día de una respuesta judicial uniforme y/o, por lo menos, clara. Además, el asunto ha sido resuelto por la Sala de lo Contencioso-Administrativo, y no por la Sala de lo Social, lo que ha provocado que el tema sea tratado principalmente desde el punto de vista del reparto de competencias y no desde la perspectiva del Derecho del Trabajo.

\section{La importancia de aplicar el convenio colectivo del lugar de ejecución en los contratos públicos}

A la hora de ejecutar un contrato público pueden coincidir en la misma obra o servicio varias empresas. De este modo, puede suceder, y así sucede en la práctica, que a pesar de ejecutar el mismo trabajo, en un mismo lugar y para la misma administración pública, los trabajadores disfruten de diferentes condiciones laborales. Ello es debido a que cada empresa adjudicataria aplica un convenio colectivo diferente, el que le corresponde en cada caso, sea de empresa, sectorial, provincial, etc. Además de dicha desigualdad, debida a la confluencia de diversos convenios colectivos, puede darse el caso de que alguno o varios de los convenios colectivos que vienen aplicando las empresas implicadas recojan condiciones laborales peores que las del convenio colectivo aplicable en el lugar que se ejecuta la obra o servicio. La consecuencia es que pueden existir trabajadores que desarrollen su trabajo con condiciones laborales inferiores a las que disfrutan los trabajadores a los que sí se les aplica el convenio colectivo del lugar de ejecución. Por supuesto, también podría darse la situación contraria. No obstante, los casos más frecuentes son los descritos en primer lugar. En este tipo de 
situaciones, la desigualdad laboral entre los trabajadores suele manifestarse, sobre todo, en materia de salarios, jornadas, vacaciones, horas extraordinarias, etc. Así, pueden confluir trabajadores que, por ejemplo, cobren el salario mínimo interprofesional con jornadas laborales larguísimas — porque así lo establece el convenio colectivo aplicable en su empresa - con trabajadores que cobren el doble con jornadas más reducidas.

Lo descrito, a pesar de que en principio goce de un respaldo normativo, no disfruta de un soporte rígido desde un punto de vista de justicia social y de los principios que rigen el Derecho, y, en concreto el Derecho del Trabajo. A saber, no es justa, ni se ajusta a Derecho, aquella situación en la que los trabajadores sufren una desigualdad laboral, solo por el hecho de pertenecer a diferentes empresas, cuando los mismos ejecutan un mismo trabajo, en el mismo lugar, bajo un mismo contrato público y para la misma administración.

Pues bien, para corregir esta posible desigualdad, se han dado varias iniciativas que promueven la incorporación de cláusulas sociales en los contratos públicos que establezcan la obligación de cumplir, para todas las empresas que resulten adjudicatarias, el convenio colectivo aplicable en el lugar de ejecución. Las mencionadas iniciativas varían, tanto en cuanto a la herramienta utilizada como en cuanto al contenido. Por un lado, se han aprobado o publicado textos políticos, instrucciones, informes... incluso normas, como es el caso de las normas forales aprobadas en las diferentes provincias del País Vasco — que son, precisamente, el objeto de las sentencias del Tribunal Supremo que van a analizarse a continuación-. Por otro lado, las iniciativas recogen o bien la obligación estricta de aplicar el convenio colectivo del lugar de ejecución del contrato público, o bien la «recomendación» de seguirlo en su plenitud o en alguno o varios de sus puntos.

Como se ha adelantado, ha sido la Sala de lo Contencioso-Administrativo del Tribunal Supremo la que ha dictado sentencias sobre las citadas normas forales. La cuestión ha sido planteada y resuelta principalmente desde el punto de vista del reparto de competencias para regular dicha materia. Por ende, como se ha dicho, el Tribunal Supremo no ha analizado todavía la temática desde el punto de vista del Derecho del Trabajo en su profundidad.

En los siguientes apartados se observará lo que ha dictado el Tribunal Supremo al respecto.

\section{Análisis de la jurisprudencia del Tribunal Supremo}

Por el momento, el Tribunal Supremo ha dictado cuatro sentencias sobre la materia. En ellas se discute sobre la legalidad de una Instrucción de la Diputación Foral de Bizkaia, una Norma Foral de Araba y otra de Gipuzkoa. Más 
concretamente, se cuestionan las competencias de la Diputación Foral de Bizkaia y las Juntas Generales de Araba y Gipuzkoa para regular la incorporación de este tipo de cláusulas.

En primer lugar, en la sentencia del 26 de noviembre de 2015, a la Sala de lo Contencioso-Administrativo del Tribunal Supremo le toca estudiar el recurso planteado por la representación de la Diputación Foral de Bizkaia contra la sentencia de 11 de julio de 2014, dictada por la Sala de lo Contencioso-Administrativo del Tribunal Superior de Justicia del País Vasco. Esta última declaró la nulidad de la Instrucción del Consejo de Gobierno de la Diputación Foral de Bizkaia de 29/10/2013, sobre Criterios de Mantenimiento de las Condiciones de Trabajo y Medidas de Carácter Social para su aplicación en los procedimientos de contratación de la Diputación Foral de Bizkaia. La Instrucción anulada pretendía intervenir sobre la reforma laboral de 2012 que modificó, entre otras cuestiones, la regulación sobre la vigencia de los convenios colectivos tras la finalización de su duración inicial pactada (ultraactividad). La Instrucción exponía que tal reforma podía conllevar la pérdida de las condiciones laborales anteriores $^{1} \mathrm{y}$, para neutralizar dicha consecuencia, establecía que en los pliegos de cláusulas administrativas particulares incluidos en los contratos dentro del ámbito de aplicación de esta Instrucción se incluirá la siguiente cláusula²:

Durante todo el periodo de ejecución del contrato, la empresa contratista está obligada a no minorar unilateralmente las condiciones de trabajo que, en materia de jornada y salario y en términos anualizados, correspondan en cada momento a los trabajadores adscritos al contrato en función del convenio colectivo que resulte de aplicación al presentarse la oferta; y ello con independencia de que tal convenio pueda posteriormente perder su vigencia en aplicación de las previsiones legales o convencionales sobre finalización de la vigencia de los convenios colectivos.

La obligación se entenderá cumplida si se mantiene el salario/hora convenio vigente en el momento inmediatamente anterior a aquel en que, en su caso, se produzca la pérdida de vigencia. El contratista vendrá obligado a facilitar al órgano de contratación cualquier información o documentación que le sea requerida para acreditar este extremo.

En todo caso, se entenderá igualmente cumplida la obligación si la reducción que eventualmente pueda producirse en el salario/hora convenio se adopta por acuerdo alcanzado entre el empresario contratista y la representación de los trabajadores ${ }^{3}$.

\footnotetext{
1 Así se recoge en la exposición de motivos de la Instrucción, que explica de forma más detallada cómo afecta la reforma laboral en el mantenimiento de las condiciones laborales y sus negativas consecuencias tanto en la merma de los derechos laborales como en el aumento de la conflictividad laboral y la reducción del consumo.

2 Artículo 5.1.a) de la Instrucción.

3 El mismo artículo recoge que "de no respetarse esta obligación, se impondrá al contratista una penalidad cuyo importe se calculará aplicando al presupuesto del contrato el porcentaje en que se haya minorado el salario/hora convenio del trabajador adscrito al contrato cuya reducción se haya operado en mayor medida hasta el limite del 10\%. De superar la reducción del salario/hora convenio del trabajador que ex-
} 
Como puede observarse, en este caso no se obliga a las empresas adjudicatarias a aplicar el convenio colectivo del lugar de trabajo, sino a mantener $-\mathrm{o}$, por lo menos, a no minorar- las condiciones laborales que correspondan a cada trabajador en función del convenio colectivo que le fuese de aplicación al presentarse la oferta.

En la sentencia recurrida, la Sala de lo Contencioso-Administrativo del Tribunal Superior de Justicia del País Vasco anuló la citada Instrucción entendiendo que la Diputación Foral de Bizkaia carece de competencia para regular sobre dicha materia ${ }^{4}$. Frente al recurso presentado por la Diputación Foral de Bizkaia contra la aludida sentencia, el Tribunal Supremo, tras una breve fundamentación jurídica, considera que no se combaten por parte de la recurrente los argumentos de la sentencia impugnada. A su parecer no se discuten debidamente los concretos preceptos que muestran que lo regulado va más allá de una simple Instrucción, al dirigirse a terceros, como lo evidencia la propia introducción de la Instrucción. Por tales motivos, declara no haber lugar al recurso de casación interpuesto. En consecuencia, el alto Tribunal no profundiza, en este caso, sobre el fondo del asunto. No obstante, la sentencia sí valora la idoneidad de las Instrucciones para regular materias de esta índole. En este sentido, opina que "no son medio idóneo para regular determinados derechos y deberes" y que cuando se establecen derechos y obligaciones para los particulares debe hacerse mediante un Reglamento. El uso de la Instrucción para incorporar este tipo de cláusulas ha generado un largo debate que, por motivos de extensión, no podemos traer a colación en este lugar 5 .

La anulación de la Instrucción no ha parado la iniciativa de la Diputación Foral de Bizkaia en esta línea. Ésta ha dado luz verde, en enero de $2017^{6}$, a un reglamento ejecutivo que permite incorporar cláusulas sociales y medioambientales al procedimiento de contratación. Eso sí, el contenido de éste no tiene nada que ver con el de la Instrucción. El reglamento ejecutivo no recoge expresamente su interés por neutralizar los negativos efectos de la ultraactividad de

perimente una mayor reducción el 10\%, o en caso de que el contratista no facilitara la información requerida para acreditar el cumplimiento de la obligación establecida en esta cláusula, se considerará incumplida una obligación esencial del contrato incurriendo el contratista en causa de resolución».

${ }^{4}$ Consigna que ni el Estatuto de Autonomía para la Comunidad Autónoma del País Vasco ni la Ley 27/1983 de Relaciones entre las Instituciones Comunes de la Comunidad Autónoma y los órganos Forales de sus Territorios Históricos, atribuyen competencia alguna a los Territorios Históricos en materia de Trabajo, Seguridad Social y Contratación.

5 Se trata de aclarar si realmente lo regulado en la Instrucción afecta o no a los particulares o, simplemente, constituye una herramienta de carácter interno con efectos «ad intra». En lo que no hay duda, y así lo defiende la doctrina judicial, es que no se permite que las Instrucciones afecten a terceros.

6 Decreto Foral n. 3/2017, de 17 de enero, para la incorporación de cláusulas sociales, medioambientales y relativas a otras políticas públicas en el procedimiento de contratación Foral de Bizkaia. 
los convenios colectivos ni los posibles contenidos de las cláusulas sociales, ni, mucho menos, como cabía esperar, una cláusula relativa al convenio colectivo a aplicar igual o similar a la recurrida ante los Tribunales (anteriormente analizada).

En segundo lugar, en la sentencia de 23 de mayo de 2016, la misma Sala tuvo ocasión de tocar el fondo del asunto, desde el punto de vista del reparto de competencias, en un caso similar. Se discute en este caso sobre la competencia de las Juntas Generales de Araba para introducir cláusulas sociales de contenido parecido al recogido en la Instrucción anteriormente mencionada. La norma a debate, en esta caso, es la Norma Foral 1/2014, de 12 de febrero, para la incorporación de cláusulas sociales en los contratos de obra del sector público foral, aprobada por las Juntas Generales de Araba.

Esta Norma Foral establece, entre otras cuestiones, que «el contratista (...) deberá aplicar las condiciones de trabajo del Convenio Colectivo de la Construcción y Obras Públicas de Álava o de los sucesivos convenios colectivos que lo revisen, en su caso (...)».

La citada norma fue recurrida también ante el Tribunal Superior de Justicia del País Vasco. La Sala de lo Contencioso-Administrativo de este Tribunal anuló el Capítulo III y el artículo 5.3 de la Norma Foral, y declaró la validez de las otras disposiciones impugnadas. Por tanto, no se anuló el artículo anteriormente indicado, esto es, el que recoge la obligación de respetar el Convenio Colectivo de la Construcción y Obras Públicas de Araba. Como era de esperar, esta sentencia fue recurrida por el Abogado del Estado que, entre otros contenidos, recurrió la cláusula referente a respetar el citado Convenio Colectivo. No obstante, en la medida en que en su recurso planteó como primer motivo de casación la falta de competencia de las Juntas Generales de Araba para aprobar normas en materia de contratación, el Tribunal Supremo entiende que corresponde analizar en primer lugar este motivo, ya que solo en el caso de que fuera rechazado procedería analizar los restantes motivos.

Pues bien, en su respectivo análisis, el alto Tribunal concluye que las Juntas Generales de Araba carecen de potestad normativa de desarrollo en materia contractual, laboral y de seguridad social, por lo que anula la norma foral alavesa en su totalidad. Para llegar a esta conclusión ofrece toda una argumentación que básicamente consiste en la afirmación de que corresponde al Estado la competencia exclusiva para dictar la legislación básica de la contratación administrativa ${ }^{8}$ y para legislar en materia laboral y la legislación básica para la Seguridad

\footnotetext{
7 Artículo 5.1 de la Norma Foral.

8 Según establece el artículo 149.1.18 de la CE, y, en apartado distinto, el 24.o, le reconoce también competencia exclusiva sobre las obras públicas de interés general o cuya realización afecte a más de una Comunidad Autónoma.
} 
Social $^{9}$. Afirma que, en el primer caso, la competencia de desarrollo de la normativa contractual está atribuida, en todo caso, a la Comunidad Autónoma ${ }^{10}$ y, en el segundo caso, sólo corresponde a la Comunidad Autónoma la ejecución de dicha legislación. Ejecución que también le está atribuida en materia de contratación administrativa ${ }^{11}$.

El Tribunal Supremo, además, profundiza en una de las cuestiones centrales en las que se basa el voto mayoritario de la sala de instancia, la naturaleza de la norma que nos ocupa y que el citado voto mayoritario no considera de carácter general. En este sentido, opina que la disposición recurrida «no tiene sólo efectos internos a modo de reglamento de autoorganización", pues tiene efectos sobre el desarrollo de los contratos y sobre los propios contratistas, "por lo que es clara la eficacia extramuros» de la misma.

En esa línea, el alto Tribunal comparte los siguientes motivos presentados por el Abogado del Estado:

1. los pliegos de cláusulas administrativas generales no son normas jurídicas, sino actos administrativos, que pueden ser impugnados por los licitadores en vía administrativa ante los Tribunales de contratación; mientras que la Norma Foral, como norma reglamentaria, sólo puede impugnarse en vía contencioso-administrativa (artículo 107 LRPJAC ${ }^{12}$;

2. los pliegos de cláusulas generales exigen dictamen previo del Consejo de Estado o del órgano consultivo equivalente de la Comunidad Autónoma (art. 114.3 LRJPAC), trámite que no exige la Norma Foral;

3. los órganos de contratación pueden establecer en el pliego de cláusulas administrativas particulares cláusulas contrarias al pliego general, previo informe de la Junta Consultiva de Contratación (art. 115.5 LCSP), posibilidad que no cabe si las cláusulas vienen impuestas por una norma jurídica, como la Norma Foral.

Según el Tribunal, lo expuesto no supone cuestionar la posibilidad de que las Juntas Generales aprueben pliegos de cláusulas administrativas generales,

lo que no pueden es hacerlo a través de una disposición de carácter general porque ello restringe la libertad de impugnación de los licitadores, y los órganos de contratación no pueden hacer uso de la facultad que les otorga el artículo 115.5 del LCSP previo informe de la Junta Consultiva de Contratación.

\footnotetext{
9 En base al artículo 149.1 , apartados $7 .^{\circ}$ y $17 .^{\circ}$.

10 Artículo 11.b) del Estatuto de Autonomía del País Vasco.

11 Artículo 12 del Estatuto de Autonomía del País Vasco.

12 Ley de Régimen Jurídico de las Administraciones Públicas y del Procedimiento Administrativo Común (Ley 30/1992, de 26 de noviembre).
} 
En consecuencia, entiende el Tribunal que se trata de una disposición de carácter general que desarrolla la legislación básica contractual del Estado, para lo que la competencia exclusiva corresponde a la Comunidad Autónoma.

En lo que respecta a estas dos últimas afirmaciones, el Tribunal no aclara ciertos parámetros y pueden plantearse las siguientes cuestiones. Por un lado, ¿podría deducirse que es posible establecer una cláusula social de tales características a través de pliegos de cláusulas administrativas generales? Por otro lado, ¿podría entonces la Comunidad Autónoma desarrollar la legislación básica contractual y establecer una cláusula de dicha índole?

En principio, las respuestas a ambas preguntas parecen afirmativas, ya que el Tribunal así lo recoge sin hacer mención especial o excepción alguna al respecto. Partiendo de tal premisa, imagínese, por ejemplo, que la norma recurrida fuese una norma de la Comunidad Autónoma, y no de las Juntas Generales de Araba, que, como en el caso de la Norma Foral, estableciese la obligación de aplicar el convenio colectivo del lugar de ejecución del contrato público en el modo descrito ¿Vulneraría el artículo 86.3 del Estatuto de los Trabajadores —es decir, el relativo a la ultraactividad de los convenios colectivos- y, debería, por ende, aplicarse el convenio colectivo de ámbito superior una vez que el aplicable hasta el momento pierda su vigencia? ¿Y menoscabaría la prioridad aplicativa del convenio de empresa (artículo 84.2 del Estatuto de los Trabajadores)?

Pues bien, como se ha mencionado al inicio del análisis de esta sentencia, el Tribunal Supremo ha condicionado el estudio de esta cuestión a la de la determinación de la competencia normativa en las materias afectadas, por lo que, una vez más, se sigue sin conocer la postura del alto Tribunal en esta temática concreta. Situación que fácilmente podría presentarse ante el mismo Tribunal, pues únicamente tendría que suceder que fuese la Comunidad Autónoma, y no las Juntas Generales de los Territorios Históricos, quien aprobase una norma de tal contenido. Habría estado bien que el Tribunal Supremo hubiese aprovechado la situación para pronunciarse también sobre esta cuestión y zanjar las dudas al respecto.

En tercer lugar, el Tribunal Supremo se pronuncia, el 31 de mayo de 2016, sobre la competencia de las Juntas Generales de Gipuzkoa para aprobar una Norma Foral de contenido parecido al de la Juntas Generales de Araba. En este caso la norma a debate es la Norma Foral 4/2013, de 17 de julio, de incorporación de cláusulas sociales en los contratos de obras del Sector Público Foral. Ésta, al igual que las anteriores, fue recurrida ante el Tribunal Superior de Justicia del País Vasco. Este Tribunal, en contra de la pretensión del Abogado General que solicitaba la nulidad de la totalidad de la Norma, dictó que únicamente extralimitaban la competencia foral: 1) el Capítulo III, que regulaba la «Verificación y evaluación del cumplimiento de las cláusulas de carácter social» y 2) el inciso 3 del artículo 5, que contemplaba el acceso a las obras de las y los repre- 
sentantes de las organizaciones sindicales representativas para llevar a cabo labores de comprobación del cumplimiento de la normativa de prevención de riesgos laborales y del resto de las condiciones de trabajo. Sin embargo, entendió que las restantes determinaciones de la Norma Foral se movían dentro del ámbito de la competencia foral o se limitaban a remitirse a la legislación vigente. Precisamente así lo entendió en el caso de la disposición de esta Norma que obliga a aplicar el Convenio Colectivo de la Construcción y Obras Públicas de Gipuzkoa, considerando que no vulnera el artículo 86.3 del Estatuto de los Trabajadores sino que únicamente se hace remisión a las particularidades sobre el régimen de vigencia de los convenios colectivos.

Por su parte, el Tribunal Supremo, ante el recurso de casación planteado por las Juntas Generales de Gipuzkoa y la Diputación Foral de Gipuzkoa contra dicha sentencia solicitando su anulación, y por tanto la validez del capítulo y artículo anulado, termina desestimándolo. Entiende que las Juntas Generales de Gipuzkoa carecen de competencia para regular tales materias. Concretamente, a su juicio, no se vulnera el artículo 37.3.a) del Estatuto de Autonomía del País Vasco — se refiere a las competencias de los territorios históricos para su organización y el régimen de funcionamiento de sus instituciones- y el artículo 11.1.b) del mismo — que apodera al País Vasco para el desarrollo legislativo de la legislación básica del Estado en materia de contratos administrativos-. A su parecer la norma foral no versa sobre esos aspectos organizativos y funcionales y no les corresponde a las Juntas Generales, sin intermediación del legislador, intervenir en el desarrollo normativo de la legislación en cuestión.

Ante esta última argumentación del alto Tribunal, podría plantease la misma pregunta indicada en el caso de la norma foral alavesa. Es decir, ¿y si lo contemplado en la norma recurrida hubiese sido prevista en una ley autonómica? Parece que se llegaría a la misma conclusión que en el caso anterior, pues tampoco en esta sentencia se dice nada más al respecto, ni se realiza matización alguna.

En cuarto y último lugar, el Tribunal Supremo vuelve a pronunciarse sobre la Norma Foral Gipuzcoana en su sentencia de 2 de junio de 2016. Como se acaba de ver, en la anterior sentencia - de 31 de mayo de 2016- este Tribunal desestima el recurso de casación presentando y reafirma lo dictado por el Tribunal Superior de Justicia del País Vasco. Esto es, que las Juntas Generales de Gipuzkoa no tienen competencia para regular las materias concretas anteriormente indicadas ${ }^{13}$, donde no se recogía la relativa a la exigencia de aplicar el convenio

13 Capítulo III, «Verificación y evaluación del cumplimiento de las cláusulas de carácter social» e inciso 3 del artículo 5, que contemplaba el acceso a las obras de las y los representantes de las organizaciones sindicales representativas para llevar a cabo labores de comprobación del cumplimiento de la normativa de prevención de riesgos laborales y del resto de las condiciones de trabajo. 
colectivo del lugar de ejecución del contrato. Es precisamente esta última cuestión la que motiva la última sentencia del Tribunal Supremo. En este caso, el Tribunal Superior de Justicia del País Vasco desestimó el recurso presentado por la Autoridad Vasca de la Competencia contra la Norma Foral guipuzcoana, declarando la validez de los artículos 4.2; 5; 6 y 7.4.a). Los artículos 4.2 y 5 son precisamente los que hacen referencia al obligado cumplimiento del Convenio Colectivo de la Construcción y Obras Públicas de Gipuzkoa.

Contra esta sentencia plantea un recurso de casación la Comunidad Autónoma del País Vasco solicitando su anulación. Tras analizar los motivos de casación interpuestos por la Administración Vasca y los motivos de oposición de las partes recurridas (Langile Abertzaleen Batzordea - LAB_- las Juntas Generales de Gipuzkoa, la Confederación Sindical ELA y la Diputación Foral de Gipuzkoa), el alto Tribunal dicta, en primer lugar, que el escrito de casación no profundiza en la crítica a los argumentos que la Sala de Bilbao, en una elaborada sentencia, expuso para desestimar el recurso de la Autoridad Vasca de la Competencia. Añade que únicamente se limita a recoger los preceptos que se consideran infringidos o las sentencias que entienden vulneradas, sin aportar razonamientos suficientes al respecto, o, cuando se aportan, resultando en todo caso mínimos. En consecuencia, el Tribunal Supremo concluye que, a pesar de que ninguna de las recurridas ha solicitado la inadmisión de los motivos de casación, dicha falta de razonamiento es suficiente para rechazarlos, por lo que procede a su inadmisión.

No obstante, la Sala va más allá, y agrega que los motivos expuestos no pueden prosperar porque la sentencia de instancia no incurre en las infracciones que se le atribuyen. Antes de explicar el porqué de esto último, el Tribunal, como no podía ser de otra manera, se ve obligado a hacer referencia a sus anteriores sentencias sobre casos similares, esto es, a las tres sentencias anteriormente aquí analizadas.

En primer lugar hace referencia a su sentencia de 31 de mayo de 2016, que es la que trata sobre la misma norma foral ahora impugnada, es decir, la norma foral guipuzcoana. Recuerda que con esta sentencia se confirmó el juicio alcanzado en instancia, reafirmando que las Juntas Generales carecen de competencia para introducir normas en materia de contratación administrativa sobre "verificación y evaluación del cumplimiento de las cláusulas de carácter social». Para ello, dice la Sala, se apoyó en su otra sentencia del 26 de noviembre de 2015, que, como se ha visto, anuló la Instrucción del Consejo de Gobierno de la Diputación Foral de Bizkaia, sobre criterios de mantenimiento de las condiciones de trabajo y medidas de carácter social para su aplicación a los procedimientos de contratación. En este caso, la Sala rechazó el motivo de casación interpuesto por la Diputación Foral de Bizkaia reprochándole no haber combatido los argumentos de instancia sobre los concretos preceptos que muestran que lo reflejado va más allá de una simple instrucción al afectar a terceros. 
Finalmente hace referencia a su sentencia de 23 de mayo de 2016, que anuló en su totalidad la Norma Foral alavesa, por la falta de competencia de las Juntas Generales de Araba para establecer normas en materia de contratación administrativa.

Tras enunciar estos tres casos, el alto Tribunal destaca que en el presente asunto no se han suscitado ninguna de las cuestiones ni los preceptos que han dado lugar a dichas sentencias. A saber, si bien en los otros se discutía sobre la competencia de la Juntas Generales o de la Diputación Foral para establecer este tipo de cláusulas sociales, en este caso se discute sobre dos ideas principales: 1) la imposición a la sumisión al último texto del Convenio Colectivo de la Construcción y Obras Públicas de Gipuzkoa vigente y, 2) la exigencia de unas determinadas condiciones de trabajo que, según el recurso, impondrían una barrera a la entrada en el mercado de contratación pública.

Pues bien, en cuanto a la primera de las ideas, el Tribunal Supremo considera que la recurrente no ha desvirtuado los argumentos expuestos en la sentencia de instancia pues «no es válido su punto de partida porque la mención a un concreto convenio por los artículos 4.2 y 5 se enmarcan en el más amplio sometimiento a la legislación laboral vigente». Así, añade que "en la medida en que esa normativa permita aplicar un convenio distinto al del lugar, tal posibilidad ha de considerarse incluida en la previsión de la norma foralı. A su juicio la Administración recurrente no explica por qué no es correcto lo afirmado por la Sala de instancia ni por qué la norma recurrida impediría la aplicación de un convenio diferente al particularmente señalado. Tampoco explicaría por qué esa sujeción a la legislación laboral vigente menoscabaría la libertad de pactos del artículo 25 de la LCSP ${ }^{14}$, ya que se trata de una cláusula a introducir en los pliegos de todos los contratos de obras del sector público foral guipuzcoano.

En lo que respecta a la segunda de las ideas, la Sala entiende que la recurrente no pone de manifiesto los presupuestos determinantes de la identidad entre este caso y los contemplados por las sentencias del TJUE que invoca. Es más, subraya que los recurridos sí han señalado la diferencia entre el asunto Rüffert y el presente: "en aquél no era un convenio de aplicación general como sí lo es éste». Finalmente, advierte que la recurrente no dice de qué manera impide la libre competencia la inclusión de esta cláusula. Por todo ello, declara no haber lugar al recurso de casación presentado por la Administración Vasca.

Como ha podido comprobarse, la jurisprudencia del Tribunal Supremo «evidencia la complejidad y conflictividad de la situación jurídica» en esta materia, que, en todo caso, confirma la doctrina mayoritaria fijada por el Tribunal Supe-

14 Ley de Contratos del Sector Público. Real Decreto Legislativo 3/2011, de 14 de noviembre, por el que se aprueba el texto refundido de la Ley de Contratos del Sector Público. 
rior de Justicia del País Vasco. Esto es, aquella que convalida este tipo de cláusulas sociales (Molina, 2016: 88) ${ }^{15}$.

\section{Conclusiones}

De las sentencias aquí analizadas puede concluirse que la posibilidad de exigir la aplicación del convenio colectivo del lugar de ejecución en la contratación pública, tal y como lo hacen la Instrucción de la Diputación Foral de Bizkaia y las normas forales de Gipuzkoa y Araba, ha sido resuelta por parte del Tribunal Supremo sobre todo en base a la competencia normativa que ostentan, o no, las Diputaciones Forales y las Juntas Generales implicadas.

Como se ha visto, el Tribunal Supremo no ha tenido que postularse en cuanto a la competencia de la Diputación Foral de Bizkaia. No obstante, sí se ha pronunciado en torno a la competencia que al respecto tienen las Juntas Generales de Gipuzkoa y Araba. Mientras que para el Tribunal Superior de Justicia del País Vasco tales Juntas sí tienen competencia para exigir, a través de cláusulas sociales introducidas en los pliegos de cláusulas administrativas particulares de todos los contratos públicos de obras, el cumplimiento del convenio colectivo del lugar de ejecución del contrato, el Tribunal Supremo rechaza tal competencia.

No obstante, se da la paradójica situación de que, mientras la norma foral alavesa se encuentra anulada en su totalidad por dicho motivo, la norma foral guipuzcoana sólo lo está parcialmente. Y, precisamente, los artículos de esta última norma que hacen referencia al cumplimiento del convenio colectivo del lugar de ejecución se encuentran actualmente en vigor. Ello, por dos motivos. Primero, porque como ya advierte el propio Tribunal Supremo en su sentencia, porque al recurrir estos preceptos no se ha interpuesto como motivo de casación la falta de competencia de las Juntas Generales. Por tanto, parece que en caso de haberlo hecho así el recurso hubiera prosperado como en el caso de la norma alavesa. Segundo, porque el recurso que pretende anular la cláusula en cuestión no razona debidamente la forma en que ésta vulnera la normativa vigente en materia de convenios colectivos, más concretamente, la relativa a la ultraactividad de los convenios y a la prioridad aplicativa del convenio de empresa.

En consecuencia, de estas sentencias, y especialmente de la analizada en último lugar, se desprende la legalidad de este tipo de cláusulas, es decir, la posibilidad de exigir el convenio colectivo del lugar de ejecución en la contratación pública. Ya que, por ahora, no se ha demostrado en qué forma vul-

15 Sobre la doctrina judicial vasca mencionada, puede consultarse Larrazabal (2015: 125-146). 
neraría la legislación laboral vigente. Eso sí, para ello, deben ser establecidas por parte de órganos que ostenten la debida competencia que, en los casos estudiados, únicamente ostentaría, como ya lo matiza el Tribunal Supremo, la Comunidad Autónoma del País Vasco, y no las Juntas Generales ni las Diputaciones Forales.

En este sentido, parece clara la idea de que, si en los casos enjuiciados se hubiese tratado de una norma autonómica, y no foral, la validez de las cláusulas no hubiese sido discutida. Partiendo de tal premisa, puede pensarse que una norma aprobada por el poder legislativo de la comunidad autónoma vasca que recogiese tal cláusula sería acorde a Derecho y no sería anulada ni por parte del Tribunal Superior de Justicia del País Vasco ni por el Tribunal Supremo. Sólo falta pues, que sea el parlamento vasco quien dé un paso adelante en este sentido y prevea tal cláusula en una ley.

Pues bien, la Comunidad Autónoma Vasca ya tiene su propia ley en materia de cláusulas sociales, la Ley 3/2016, de 7 de abril, para la inclusión de determinadas cláusulas sociales en la contratación pública, aprobada por el parlamento vasco. Sin embargo, ésta no hace referencia alguna a la posibilidad de exigir el cumplimiento del convenio colectivo del lugar de ejecución del contrato. Puede que ello se deba a que el parlamento vasco no se atrevió a recoger una cláusula cuyo contenido se encontraba recurrido, a raíz de la norma foral guipuzcoana, ante el Tribunal Supremo, pues la Ley es algo anterior al último fallo del alto Tribunal. O puede que, simplemente, el parlamento vasco no haya querido incluir una cláusula de tales características, por diversos motivos.

La Ley vasca únicamente establece que «los pliegos de cláusulas administrativas particulares incorporarán la advertencia de que el contrato se halla sujeto al cumplimiento de las disposiciones legales, reglamentarias y convencionales vigentes $y$ que resulten de aplicación en materia laboral (...)” ${ }^{16}$, que dichos pliegos incorporarán la obligación de que los licitadores «indiquen el convenio colectivo que será de aplicación a los trabajadores y trabajadoras que realicen la actividad objeto del contrato (...)", así como la obligación de "facilitar cuanta información se requiera sobre las condiciones de trabajo (...) ${ }^{17}$ y que, el adjudicatario «deberá, a lo largo de toda la ejecución del contrato, abonar el salario recogido en el convenio colectivo de aplicación según categoría profesional que le corresponda a la persona trabajadora (...) » ${ }^{18}$. En fin, esta Ley no hace nada más que enfatizar en la obligación de cumplir la normativa laboral vigente y establecer el deber de indicar el convenio colectivo que la adjudicataria aplicará a sus trabajadores así como la de abonar el salario recogido en el mismo. Nada relevante.

\footnotetext{
16 Artículo 5.1 de la Ley Vasca aludida.

17 Artículo 5.2 de la misma Ley Vasca.

18 Artículo 5.3 de la Ley Vasca.
} 
Tras la última sentencia del Tribunal Supremo, parece que no hay excusa para no contemplar, mediante una ley, lo ya recogido en la norma foral guipuzcoana actualmente en vigor, esto es, la aplicación del convenio colectivo del lugar de ejecución del contrato. Además, a tal fin, se cuenta con el aval de la jurisprudencia del Tribunal de Justicia de la Unión Europea, ya que debido al giro interpretativo experimentado en esta materia es posible obligar a los licitadores y a sus subcontratistas a comprometerse a pagar al personal que llevará a cabo las prestaciones objeto del contrato público el salario fijado en una norma regional ${ }^{19}$. Lo que, aplicándolo al caso aquí analizado, podría traducirse en la exigencia, recogida en una norma regional, de aplicar el convenio colectivo de eficacia general del lugar de ejecución.

En este contexto, es necesario destacar que hoy día ya existe una Ley autonómica que recoge una cláusula de casi igual contenido que la descrita anteriormente. Se trata de la Ley Foral 6/2006 navarra, de Contratos Públicos. El Pleno del Parlamento de Navarra aprobó el 15 de enero de 2015, por unanimidad, la Ley Foral de modificación de la Ley 6/2006, de Contratos Públicos, para la introducción de cláusulas sociales en los contratos públicos. Ésta tiene su origen en una Iniciativa Legislativa Popular, la misma que fue presentada en el Parlamento Vasco, pero que, por diferentes motivos, no ha visto la luz en la Comunidad Autónoma Vasca, ya que, como se ha visto, la Ley Vasca no exige el cumplimiento del «último convenio colectivo sectorial de el ámbito más inferior existente en el sector en el que se encuadre la actividad de la empresa contratista", como sí lo hace la Ley Foral navarra ${ }^{20}$. Lo más peculiar de todo esto es que la Ley navarra no ha sido recurrida, como sí lo han sido las normas forales vascas anteriormente analizadas.

En fin, en principio no cabría duda de la legitimidad de la Comunidad Autónoma Vasca para aprobar una Ley que establezca una cláusula social en el sentido indicado, tanto por que la jurisprudencia del Tribunal Supremo así lo avala como por el ejemplo de la Ley en vigor en su vecina comunidad autónoma navarra.

19 Sentencia del Tribunal de Justicia de la Unión Europea de 17 de noviembre de 2015, caso RegioPost. Para un análisis de este caso, véase Moreno (2016: 106-109), Miranda (2016: 69-91), Toscani y Valenciano (2016: 89-105), Vázquez (2016: 28-41).

20 Artículo 3.1.a) de la Ley Foral 1/2015, de 22 de enero, por la que se modifica la Ley Foral 6/2006, de 9 de junio, de contratos públicos, para la introducción de cláusulas sociales en los pliegos de cláusulas administrativas. La cláusula en cuestión se recoge, tras la modificación, en el artículo 49 «requerimientos de carácter social o medioambiental en la ejecución de los contratos» de la Ley Foral $6 / 2006$ 


\section{Bibliografía}

Larrazabal Astigarraga, Eider (2015), «La introducción del salario mínimo en la contratación pública: análisis jurisprudencial del TJUE y del TSJPV», Revista de Derecho Social, n. ${ }^{\circ}$ 71, pp. 125-146.

Miranda Boto, José María (2016): «Contratación Pública y cláusulas de empleo y condiciones de trabajo en el Derecho de la Unión Europea», Lex Social: revista de los derechos sociales, n. ${ }^{\circ}$ 2, pp. 69-91.

Molina Navarrete, Cristóbal (2016): «Cláusulas sociales, contratación pública: del problema de "legitimidad» al de sus "límites»», Temas laborales: Revista andaluza de trabajo y bienestar social, n. ${ }^{\circ} 135$, pp. 79-110.

Moreno Molina, José Antonio (2016): «Se puede obligar a los licitadores y a sus subcontratistas a pagar un salario mínimo determinado al personal que llevará a cabo las prestaciones?», Contratación administrativa práctica: revista de la contratación administrativa y de los contratistas, n. ${ }^{\circ} 141$, pp. 106-109.

Toscani Giménez, Daniel y Valenciano Sal, Antonio (2016): «Cambio de criterio del TJUE ante la posibilidad de fijar un salario mínimo a respetar en la ejecución de contratos en el ámbito de la contratación pública: comentario a la Sentencia del Tribunal de Justicia de la Unión Europea. Asunto C-115/14 (RegioPost GmbH amp; Co KG / Stadt Landau in der Pfalz) de 17 de noviembre de 2015", Unión Europea Aranzadi, n. ${ }^{\circ}$ 1, pp. 89-105.

VÁzquez LacunZa, Estela (2016): «El pago de un salario mínimo como condición especial de ejecución en los contratos públicos», Contratación administrativa práctica: revista de la contratación administrativa y de los contratistas, n. ${ }^{\circ} 146$, pp. 28-41. 